\title{
aniki
}

Revista Portuguesa da Imagem em Movimento

Portuguese Journal of the Moving Image

\section{Sobre Cinema El Dorado - Cinema e Modernidade} Elisabete Marques ${ }^{1}$

Guerreiro, Fernando. 2015. Cinema El Dorado - Cinema e Modernidade. Lisboa: Edições Colibri. 410 pp. ISBN: 978-989-689-548-8.

Publicado em novembro de 2015, Cinema El Dorado - Cinema e Modernidade, de Fernando Guerreiro, contou com alguma receção crítica, embora claramente insuficiente, tendo em conta as características do livro e o seu programa ambicioso, plasmado na estrutura e no arcabouço conceptual e bibliográfico a que recorre.

Em Cinema El Dorado, Guerreiro propõe um itinerário singular para a apreensão do fenómeno do cinema em toda a sua complexidade: abrangendo o seu estado mais embrionário, enquanto ideia ou desejo, bem como a sua concretização através dos mais variados dispositivos e modos de se reinventar.

Não espanta, assim, a estruturação do livro em cinco partes, com os seguintes títulos e ordenação: I. Dispositivos, II. Cinemobiles, III. Fotogenias, IV. Aparições, V. Ecoplastias. Corresponde a primeira secção ao estudo dos contextos que precederam o anúncio oficial do nascimento do cinema; a segunda à análise da receção desta nova técnica por parte dos diferentes modernismos (em Portugal e em França); a terceira, à análise da receção por parte das elites culturais e ao estudo do pensamento das vanguardas; a quarta à reflexão do cinema de Manoel de Oliveira (marcado pelos valores da modernidade); a quinta à sintetização de alguns tópicos tematizados anteriormente. Existe ainda uma sexta parte, "Nota de Edição", na qual se esclarece a proveniência dos diferentes capítulos.

Conforme se verifica, Guerreiro não segue uma cronologia que remeta o surgimento do cinema à exibição pública de 28 de dezembro de 1895 (pelos irmãos Lumière); considera antes que, "desde a segunda metade do século XVIII, o Cinema está a vir, na Literatura" (13). Daí que o capítulo inicial do livro se intitule «Diderot e o Cinema». Nele, o autor comenta o aparecimento dos vários dispositivos de projeção anteriores ao cinematógrafo (que teriam afetado os modos de perceção dos espectadores), mas pondera também algumas figuras de retórica, como a prosopopeia e a hipotipose, que acentuam a visualidade (móvel) em causa na linguagem. Assim, no contexto da valorização do sensorial e do

\footnotetext{
${ }^{1}$ Universidade do Porto, Faculdade de Letras, Instituto de Literatura Comparada Margarida Losa, 4150-564, Porto, Portugal.
} 
sensível patente nos ensaios de estética (à época, disciplina recémfundada por Alexander Gottlieb Baumgarten), das inovações técnicas e dos novos modos de perceção daí decorrentes, Diderot ensaia uma escrita antecipadamente "cinematográfica" no seu texto "Promenade Vernet". Nele, passar-se-ia de uma descrição denotativa (figurativa) de quadros para o registo da ficção (figural), ou seja, para uma "hipotipose animada", não só retórica mas sensacionalista: anima-se o quadro e a descrição é um dispositivo de projeção que faz ver mentalmente. No entender do autor de Cinema El Dorado, tratase de "uma construção cinematográfica do discurso (com recurso a travellings, panorâmicas, grandes-planos, montagem de atracções) que [...] faz da "Promenade" um travelling panorâmico" (19).

Contudo, a relação de Diderot com o cinema não se cinge ao modo como pensa a escrita (de quadros), já que a tese da quarta parede, com a qual se pretende criar um efeito de real ("natural") no palco, antecipa-o e influencia-o. Uma das consequências da quarta parede no teatro seria, segundo Guerreiro, a "autonomização da dimensão visual da cena”, quase à maneira do quadro. No entanto, devido ao movimento dos corpos, produz-se em cena um efeito de hipotipose em ação (quadro vivo), com grande aproximação ao cinema.

Aproveitada, repensada e reelaborada teoricamente por alguns cineastas como Griffith e Eisenstein (para quem o cinema cumpre as promessas do teatro), a quarta parede parece concretizarse no cinema. Nele acontece uma efetiva separação entre plateia e atores. Acresce que, privado do som (da fala), o cinema depende inteiramente da expressividade dos corpos, através da qual se transmitem as emoções e as ideias. É, assim, uma pura arte da pantomima, um drama mudo das imagens. A acentuação da expressividade patética (pathos) no e do cinema resulta a um só tempo na proliferação de discursos teorizantes e no processo de autonomização da linguagem cinematográfica. Para Guerreiro, os modos de perceber o real também se alteram (marcados pelo mais recente olhar cinematográfico), e tais alterações são passíveis de serem vislumbradas nas obras dos artistas da época.

A segunda parte será, pois, dedicada à análise das relações de movimentos e autores modernistas com o cinema, as quais, não raras vezes, acontecem por mediação de outras práticas artísticas (desenho, pintura, teatro, escultura, arquitetura, dança, música). No primeiro capítulo, o futurismo é tematizado como fenómeno transnacional (e acontecimento, que a par do cinema, teria sido marcante para os modernismos portugueses, 150), procedendo-se, nos capítulos seguintes, à análise de casos portugueses, como os dos autores de Orpheu (Fernando Pessoa, Mário de Sá-Carneiro, António Ferro, Almada Negreiros) e da Presença (José Régio e Adolfo Casais Monteiro); de permeio, integra-se um texto sobre o Filme do Desassossego (2010), de João Botelho. Encontramos nestas páginas a 
descrição de um conjunto de poéticas/estéticas distintas que não podem deixar de ponderar e até de assimilar o cinema nas suas práticas, contagiadas pelos novos processos de fazer, de lançar, de sentir e de pensar as imagens. Assim, destaca-se em Mário de SáCarneiro o desejo de uma poesia aérea, feita de "poemas sem suporte [...] dotados de uma estrutura "molecular"” (99) ou, em Ferro, a defesa de uma arte dos fluxos e dos simulacros (112). No caso de Pessoa, assinala-se a sua compreensão da "dimensão espectral” (125) do cinema. Para o poeta, o cinema é espectral, na medida em que se assiste nele à "dissolução da fenomenalidade"; no entanto, e "paradoxalmente, [o cinema] dá espessura ao real e à sua experiência" (127). Seria nessa medida que se aproximaria da estética sensacionalista (Álvaro de Campos) e dos modos de perceção do real que encontramos no Livro do Desassossego, de Bernardo Soares. O Filme do Desassossego, de João Botelho, estaria em consonância e trabalharia cinematograficamente estas duas tendências, bem como a fragmentação (atomização) do livro (montado) de Pessoa.

Quanto a Almada Negreiros, a relação que mantém com o cinema pode ser pensada a partir das suas reflexões sobre a animação. Segundo Almada, a animação corresponde a uma nova expressão artística do cinema porque introduz nele a dimensão do imaginário, afastando-o da mecânica (do registo). Estaria ainda em causa na animação a emancipação do desenho relativamente à sua condição estática, fixada: tratar-se-ia de um desenho dançante, vivificado pelo movimento. Da mesma forma, e considerado o seu estatuto de artista multifacetado e performativo, na produção artística de Almada é possível vislumbrar um cinema das formas em ato: "uma acção cinema" (itálico do autor, 170).

$\mathrm{Na}$ terceira parte, "Fotogenias", Guerreiro analisa, num primeiro momento, a receção do cinema pelas elites culturais e artísticas da Europa nas duas primeiras décadas do século XX, assinalando os casos de entusiasmo (Cendrars, Léger, Clair, Moussinac, Colette, Joyce) e os de franca desconfiança, senão mesmo rejeição (Kafka, Chesterton, Pessoa, Musil). Será também aí estudado o impacto que alguns eventos, como a Primeira Grande Guerra, tiveram no pensamento da técnica e nos modos de perceção conduziram, a um só tempo, a um novo entendimento do cinema e a uma alteração das formas, como seja a "concepção maquínica da poesia" (198). Os caligramas de Apollinaire surgem como exemplo paradigmático desse novo modo de pensar e de fazer poesia: "exemplo por excelência de um 'lirismo visual' e de uma poesia sintética, plástica e criacionista, na linha das “"palavras em liberdade' futuristas" (198).

$\mathrm{O}$ autor examina ainda as diferentes teses de cineastas franceses da década de 1920 (Gance, Epstein, Delluc), os quais, 
segundo Guerreiro, procurariam um outro cinema, já não da mimese ou da figuração, mas um "cinema vivo", "das formas vivas" (224).

$\mathrm{Na}$ esteira do que havia anteriormente tratado (os efeitos da guerra, a emergência das vanguardas, as diferentes estéticas, conceções de imagem e de cinema daí resultantes), nos três capítulos seguintes, Guerreiro analisa em pormenor filmes de três cineastas. São eles J'Accuse (1919 e 1938), de Abel Gance, El Dorado (1921), de Marcel L'Herbier e The Fall of the House of Usher (1928), de Jean Epstein. É, aliás, da obra de L'Herbier que retira o título do livro e o fotograma que aparece na capa (o plano final do filme). O fotograma em causa funcionaria como ideograma ou hieróglifo, isto é, imagem saturada (284) - como veremos, esta ideia é de máxima relevância para o autor.

$\mathrm{Na}$ quarta parte, intitulada "Aparições", incluem-se três capítulos dedicados à filmografia de Manoel de Oliveira. De entre a extensa obra deste realizador, Guerreiro seleciona para analisar Douro, Faina Fluvial (1931), O Pintor e a Cidade (1956), Acto de Primavera (1963), O Passado e o Presente (1971), Benilde ou a Virgem Mãe (1974), Espelho Mágico (2005) e O Estranho Caso de Angélica (2010). Esta secção, que poderia parecer algo despropositada no livro, revela-se coerente, na medida em que Guerreiro observa na obra de Oliveira alguns dos motivos da modernidade. Neste conjunto, examina as ligações e intercâmbios dos filmes de Oliveira com a pintura, o teatro, a literatura e a fotografia. No entanto, a análise amplificará as leituras mais convencionais e procurará dar conta de uma outra força desta obra: a de se constituir como cinema da mostração, da aparição (espectral e de sonho), de que $O$ Estranho Caso de Angélica é o mais contundente exemplo.

Chegados à última secção do livro, "Ecoplastias", o autor oferece algumas páginas de síntese. Nelas se lê um esclarecimento sobre a sua ideia de "imagem-folhada": uma vez que a imagem de cinema não corresponde a um simples decalque do objeto, mas é antes heterogénea, funciona "como corpo [...] folhado de espectros (simulacros)" (itálico do autor, 391), que "dá a ver "o trabalho (invisível) do mundo". Para além da sua natureza ontológica incerta, indeterminada (entre o material e o imaterial, entre a figura e o figural), a imagem do cinema constrói-se por camadas, por sobreimpressões (imagéticas) e pela sedimentação de estratos feitos de matérias distintas. É nesse sentido que o autor trabalha a noção de imagem-hieróglifo (ideograma multisignificativo, compósito, polissémico) de Eisenstein, retomada por Marie-Claire RoparsWuilleumier e por Tom Conley.

Guerreiro termina mostrando como, em termos formais, esse carácter de "dobra" (folhado) da imagem não deve ser pensado apenas em função de "momentos-ícone" (399), mas como premissa estética "para todo o filme" (399). Fá-lo-á recorrendo aos exemplos 
do expressionismo alemão e, mais próximo de nós, dos filmes Cave of the Forgotten Dreams (2011) e Into the Abyss/ A Tale of Death, a Tale of Life (2012) de Werner Herzog. Esclarece o autor que: "O cinema enquanto instalação real (dada a sua qualidade de "presente") e imaginária [...] restitui o tecido da totalidade redentora do mundo, ao mesmo tempo que constitui o lugar e a dobra (sensorial, física) da sua apresentação" (itálico do autor, 402-403). O cinema funcionaria como um palimpsesto de texturas, um hieróglifo que cabe ao espectador reinventar de cada vez.

Livro extenso, complexo, por vezes labiríntico, não é fácil sintetizá-lo ou reduzi-lo a uma tese. Cinema El Dorado é múltiplo, rizomático, compósito e estratificado, notável pela erudição, pela presença maciça de referência e de notas de rodapé (que constituem como que um texto paralelo). A articulação dos argumentos é amiúde opaca. E a escrita, hifenizada e parentética, exige do leitor atenção redobrada e tenacidade no exercício de descodificação. Estas características, efeitos de um estilo fluido e do interesse quase nulo pelas convenções do tratado académico, pressupõem um leitor ativo e criador, mais do que passivo e recetor.

Lamente-se o facto de não existir uma bibliografia final. As referências bibliográficas são apresentadas em notas de rodapé, sendo que, após a primeira ocorrência, o autor se limita a indicar título e página (ou mesmo apenas a página): esta solução resulta, não raras vezes, no completo desamparo do leitor. Para além de facilitar o acompanhamento das matérias do livro, uma bibliografia final num trabalho desta envergadura (com 410 páginas) constituiria uma ferramenta útil para quem pretendesse dedicar-se aos tópicos tratados.

Apesar da dificuldade e da resistência que por vezes oferece à leitura, trata-se de um trabalho incontornável que enriquece a bibliografia dos estudos de cinema em Portugal, sucedendo tematicamente aos livros de Rosa Maria Martelo, O Cinema da Poesia (2012) e de Joana Matos Frias, Cinefilia e Cinefobia no Modernismo Português (2015).

\section{BIBLIOGRAFIA}

Frias, Joana Matos. 2015. Cinefilia e Cinefobia no Modernismo Português. Porto: Afrontamento.

Guerreiro, Fernando. 2015. Cinema El Dorado - Cinema $e$ Modernidade. Lisboa: Edições Colibri.

Martelo, Rosa Maria. 2012. O Cinema da Poesia. Lisboa: Documenta. 